\title{
Incorporação de lama de mármore e granito em massas argilosas
}

\section{(Incorporation of marble and granite sludge in clay materials)}

\author{
J. B. Silva', D. Hotza', A. M. Segadães ${ }^{3}$ W. Acchar ${ }^{4}$ \\ ${ }^{1}$ Universidade Federal do Rio Grande do Norte (PGEM) \\ Natal, RN, Brasil 59072-970 \\ ${ }^{2}$ Departamento de Engenharia Química, Universidade Federal de Santa Catarina \\ Florianópolis, SC, Brasil 88040-900 \\ ${ }^{3}$ Departamento de Engenharia Cerâmica e do Vidro (CICECO), Universidade de Aveiro \\ Aveiro, Portugal 3810-193 \\ ${ }^{4}$ Departamento de Física, Universidade Federal do Rio Grande do Norte \\ Natal, RN, Brasil 59072-970
}

\begin{abstract}
Resumo
A utilização de resíduos industriais como aditivos na fabricação de produtos cerâmicos vem despertando um crescente interesse dos pesquisadores nos últimos anos e está se tornando prática comum. Este trabalho descreve a variação do comportamento de uma argila utilizada numa indústria de cerâmica vermelha, resultante de adições de uma lama de mármore e granito, tal como é produzida em uma indústria de beneficiamento de pedras ornamentais do estado do Rio Grande do Norte. Misturas de argila e rejeito $\left(10-50 \%\right.$ em peso) foram compactadas uniaxialmente e sinterizadas a temperaturas entre 950 e $1150{ }^{\circ} \mathrm{C}$. Os resultados obtidos por análise química e mineralógica (DRX e FRX), análises térmicas (DTA, TG e dilatometria), medidas de distribuição granulométrica, porosidade, absorção de água e tensão de ruptura à flexão, revelam que a lama de mármore e granito pode ser incorporada na massa de argila sem perda ou comprometimento das propriedades dos corpos sinterizados de cerâmica vermelha.

Palavras-chave: lama de mármore e granito, cerâmica vermelha, reciclagem.
\end{abstract}

\begin{abstract}
The use of industrial waste materials as additives in the manufacture of ceramic products has been attracting a growing interest from researchers in recent years and is becoming common practice. This work describes the changes in the behavior of the clay material used in a red-ceramic industry due to additions of a granite and marble sludge, produced in an ornamental stone processing industry in Rio Grande do Norte. Mixtures of clay and waste material (10-50 wt.\%) were uniaxially pressed and sintered at temperatures ranging from 950 to $1150^{\circ} \mathrm{C}$. Results from chemical and mineralogical analysis (XRD and XRF), thermal analysis (DTA, TG and dilatometry), particle size distribution, porosity, water absorption and flexural strength, show that the granite and marble sludge can be added to the clay material with no detrimental effect on the properties of the sintered red-clay products.
\end{abstract}

Keywords: granite and marble sludge, red-clay ceramics, recycling.

\section{INTRODUÇÃO}

A literatura recente tem referências a vários trabalhos descrevendo o estudo dos efeitos da adição de alguns rejeitos industriais (como borra de petróleo, cinzas de carvão, resíduos urbanos, granito, lodo da indústria têxtil) a massas argilosas [1-8]. Os resultados mostram que a heterogeneidade dos produtos cerâmicos tradicionais permite a incorporação de uma quantidade razoável desses rejeitos sem prejuízo das propriedades dos produtos finais e com o alívio muito bemvindo das preocupações com o descarte dos rejeitos. Mesmo quando as quantidades adicionadas são pequenas, a grande quantidade de produtos cerâmicos fabricados traduz-se num consumo significativo de rejeitos. Além disso, atendendo às relativamente elevadas temperaturas de queima $\left(>1000^{\circ} \mathrm{C}\right)$, a incorporação do rejeito na matriz cerâmica é efetiva, o que é particularmente interessante quando se pretende tornar inertes rejeitos perigosos.

A indústria de beneficiamento de mármore e granito vem despertando cada vez mais o interesse dos ambientalistas. Nas diversas etapas de produção (nomeadamente, extração, corte, serragem e polimento dos blocos de pedra), as perdas podem ser da ordem de 30 a $40 \%$ [9]. Atualmente, e em grande parte dos casos, não existe nenhuma preocupação com o meio ambiente, sendo o rejeito jogado diretamente em lagoas e rios, sem nenhum tratamento prévio, o que, apesar de as lamas de serragem não serem consideradas resíduo perigoso (classe I), constitui um sério problema ambiental.

A indústria de mármore e granito do estado do Rio Grande do Norte produzuma quantidade razoável de rejeito, ainda não quantificado no estado, cujo uso em massas cerâmicas pode não só amenizar um grave problema ambiental como também 
significar uma fonte alternativa de matéria-prima para o setor cerâmico. O estado do Espírito Santo, maior explorador do setor, estima que a produção de lama abrasiva de mármore e granito das industriais da região esteja em torno de 4000 toneladas por mês. $\mathrm{O}$ mármore é um calcário metamórfico cristalino, basicamente constituído por calcita $\left(\mathrm{CaCO}_{3}\right)$ e o granito é uma rocha ígnea, constituída principalmente por feldspatos, quartzo e micas. Em geral, resíduos de mármore e granito apresentam um comportamento não plástico e, tal como a grande maioria dos materiais cerâmicos tradicionais, seus constituintes químicos majoritários, expressos na forma de óxidos, são a silica $\left(\mathrm{SiO}_{2}\right)$ e a alumina $\left(\mathrm{Al}_{2} \mathrm{O}_{3}\right)$, seguidos pela cal $(\mathrm{CaO})$ e os óxidos alcalinos $\left(\mathrm{Na}_{2} \mathrm{O}, \mathrm{K}_{2} \mathrm{O}\right)$. Os teores de óxidos de ferro também podem ser significativos, mas o seu papel durante o processamento não é tão importante (são fundentes só a altas temperaturas).

Portanto, este tipo de rejeito industrial apresenta um bom potencial para ser incorporado em massas argilosas destinadas à produção de materiais cerâmicos tradicionais [10]. O objetivo deste trabalho é estudar o efeito da incorporação do rejeito produzido no processo de corte, serragem e polimento das pedras de granito e mármore em massas argilosas, o que contribuiria para o desenvolvimento sustentável do setor.

\section{EXPERIMENTAL}

Neste trabalho, utilizou-se uma argila em torrões, coletada na indústria Cerâmica de São Gonçalo do Amarante, RN, e rejeito da indústria de beneficiamento de mármores e granitos do estado do Rio Grande do Norte. O rejeito, sob a forma de lama, foi primeiramente seco em estufa, sendo depois moído em moinho de bolas. A argila foi moída e passada em peneira de 60 mesh. Misturas contendo argila e rejeito de mármore e granito em concentrações variando entre $10 \mathrm{e}$ $50 \%$ em peso, foram homogeneizadas em moinho de bolas e compactadas uniaxialmente em matriz metálica com uma pressão de compactação de $50 \mathrm{MPa}$, sob a forma de corpos de prova prismáticos de $100 \times 10 \times 10 \mathrm{~mm}^{3}$. A adição de diferentes concentrações de rejeito resulta numa resposta de compactação diferente para as várias massas e, portanto, diferentes níveis de porosidade inicial dos corpos verdes. A utilização de uma pressão de compactação relativamente elevada teve por objetivo atenuar essas diferenças de modo a que as propriedades finais dos corpos sinterizados fossem pouco afetadas.
Os corpos de prova foram sinterizados ao ar em forno resistivo a temperaturas entre 950 e $1150{ }^{\circ} \mathrm{C}$ durante 2 horas, com taxa de aquecimento de $10^{\circ} \mathrm{C} / \mathrm{min}$.

A composição química das matérias-primas foi determinada por fluorescência de raios X (Shimadzu, EDX700) e a análise granulométrica foi feita em um granulômetro a laser (Cilas 930L). A análise das fases cristalinas nos materiais foi determinada por difração de raios X (Shimadzu, XRD-600). As análises térmicas (Shimadzu, Diferential Thermal Analyzer DTA-50 e Thermogravimetric Analyzer TGA-51) foram realizadas com velocidade de aquecimento de $10{ }^{\circ} \mathrm{C} / \mathrm{min}$, sob o fluxo constante de $50 \mathrm{~mL} / \mathrm{min}$ de ar sintético. Os ensaios de dilatometria foram realizados também com velocidade de aquecimento de $10{ }^{\circ} \mathrm{C} / \mathrm{min}$ (BP Engenharia, dilatômetro RB-3000).

Os corpos cerâmicos sinterizados foram caracterizados quanto a absorção de água (ABNT NBR 6480-85) e massa específica aparente (método de Arquimedes em água) [11], fases cristalinas presentes (difração de raios X) e tensão de ruptura à flexão em três pontos (Shimadzu, Autograph-AGI, $250 \mathrm{kN}$ ), segundo as normas NBR 6462-97 da ABNT [12] e DIN 51090 [13].

\section{RESULTADOS E DISCUSSÃO}

A Tabela I apresenta a composição química, expressa em óxidos, das matérias-primas utilizadas. A argila estudada tem uma composição típica deste tipo de materiais, ou seja, é rica em sílica e alumina (apresentando teores muito inferiores de óxidos de $\mathrm{Ti}, \mathrm{Ca}, \mathrm{Mg}, \mathrm{Na}, \mathrm{K}$ e $\mathrm{Mn}$ ). A perda ao fogo de $7,60 \%$ está dentro da faixa habitual para as argilas usadas em cerâmica vermelha, geralmente associada a perda de constituintes voláteis, queima de matéria orgânica e decomposição de carbonatos [14]. O componente minoritário principal é o óxido de ferro, presente em um teor particularmente elevado (11,66\%), que irá conferir aos corpos queimados uma coloração escura. O rejeito de mármore e granito é constituído predominantemente também por sílica e alumina, mas destaca-se por conter teores elevados de $\mathrm{CaO}$ $(19,92 \%)$ e de óxidos fundentes $(11,39 \%)$. Estes óxidos irão ter influência marcante durante a queima, promovendo a formação de fase líquida e favorecendo a sinterização e a densificação. A perda ao fogo do rejeito é mais baixa do que a que seria esperada se todo o $\mathrm{CaO}$ fosse proveniente da calcita $\left(\mathrm{CaCO}_{3}\right)$. Isto é indicativo da presença de outros materiais contendo cálcio. A presença do óxido de ferro $(3,56 \%)$ pode

Tabela I - Composição química (\% em peso) das matérias-primas.

[Table I - Chemical composition (wt.\%) of the raw materials.]

\begin{tabular}{ccccccccccccc}
\hline & $\mathrm{PF}^{*}$ & $\mathrm{SiO}_{2}$ & $\mathrm{Al}_{2} \mathrm{O}_{3}$ & $\mathrm{Fe}_{2} \mathrm{O}_{3}$ & $\mathrm{CaO}$ & $\mathrm{K}_{2} \mathrm{O}$ & $\mathrm{MgO}$ & $\mathrm{Na}_{2} \mathrm{O}$ & $\mathrm{TiO}_{2}$ & $\mathrm{MnO}$ & $\mathrm{P}_{2} \mathrm{O}_{5}$ & $\mathrm{~V}_{2} \mathrm{O}_{5}$ \\
\hline Argila & 7,60 & 41,74 & 27,36 & 11,66 & 1,37 & 1,63 & 2,79 & 0,77 & 0,60 & 0,17 & 0,11 & 0,20 \\
Rejeito & 12,37 & 37,86 & 13,65 & 3,56 & 19,92 & 4,32 & 3,49 & 3,58 & 0,61 & 0,07 & 0,24 & vestíg. \\
\hline
\end{tabular}

* PF = Perda ao Fogo 
estar relacionada com a granalha normalmente utilizada no corte/polimento de pedras ornamentais. Conforme a Tabela I mostra, adições de rejeito à argila originam alterações significativas apenas dos teores dos óxidos de cálcio e de ferro e da perda ao fogo, mantendo-se a sílica e a alumina como componentes majoritários.

A Fig. 1 mostra os difratogramas de raios $\mathrm{X}$ da argila $\mathrm{e}$ do rejeito. Verifica-se que a argila é constituída principalmente por quartzo e ilita. Podem ser observados também picos pouco intensos de muscovita $\left((\mathrm{K}, \mathrm{Na})(\mathrm{Al}, \mathrm{Mg}, \mathrm{Fe}) \cdot 2\left(\mathrm{Si}_{3} \mathrm{Al}_{0.9} \mathrm{O}_{10}\left(\mathrm{OH}_{2}\right)\right)\right.$, ortoclase $\left((\mathrm{K}, \mathrm{Ba}, \mathrm{Na})(\mathrm{Si}, \mathrm{Al})_{4} \mathrm{O}_{8}\right)$ e hematita $\left(\mathrm{Fe}_{2} \mathrm{O}_{3}\right)$. O rejeito é constituído essencialmente por quartzo, anortita $\left(\mathrm{CaAl}_{2} \mathrm{Si}_{2} \mathrm{O}_{8}\right)$, calcita $\left(\mathrm{CaCO}_{3}\right)$ e dolomita $\left(\mathrm{CaMg}\left(\mathrm{CO}_{3}\right)_{2}\right)$, notando-se picos menos intensos de hematita, albita $\left(\mathrm{NaAlSi}_{3} \mathrm{O}_{8}\right)$ e microclina $\left(\mathrm{KAlSi}_{3} \mathrm{O}_{8}\right)$. A presença de anortita explica a discrepância entre os valores encontrados para a perda ao fogo e o teor de $\mathrm{CaO}$, e a dolomita é responsável pelo teor de $\mathrm{MgO}$. Assim, as fases cristalinas identificadas confirmam as composições químicas apresentadas na Tabela I.

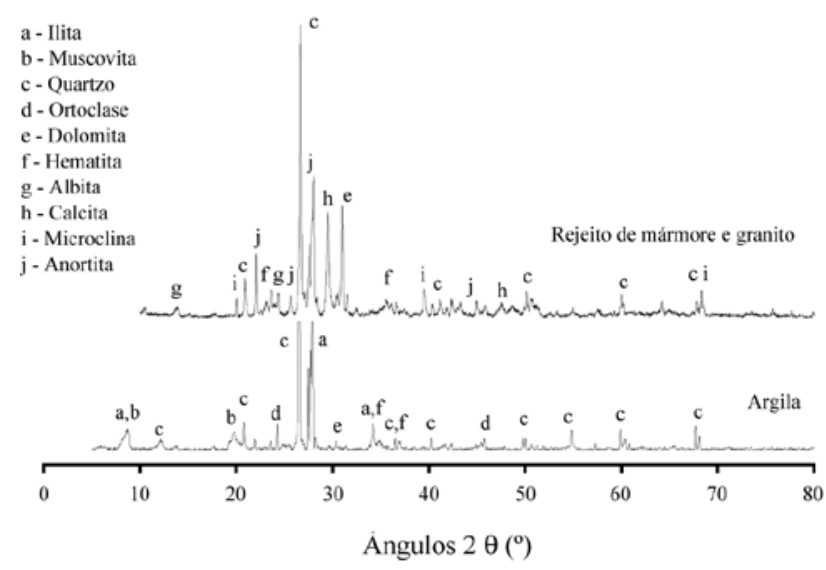

Figura 1: Difratogramas de raios $\mathrm{X}$ das matérias-primas. [Figure 1: X-ray diffraction patterns of the raw materials.]

A Fig. 2 mostra o comportamento térmico (ATD e ATG) do rejeito de mármore e granito, que está em concordância com os resultados de difração de raios X. A análise termogravimétrica mostra uma ligeira perda de massa de $0,2 \%$ entre 40 e $100{ }^{\circ} \mathrm{C}$, correspondente à perda de água livre, outra de $1,73 \%$ entre 100 e $700{ }^{\circ} \mathrm{C}$, relativa à perda de água adsorvida, e uma perda acentuada de $10,61 \%$ entre 700 e $880{ }^{\circ} \mathrm{C}$, que pode ser atribuída a decomposição dos carbonatos (calcita e dolomita). Podem-se notar na análise térmica diferencial os picos endotérmicos correspondentes, a $43,4{ }^{\circ} \mathrm{C}$ e $769,1^{\circ} \mathrm{C}$ (perda de água livre e decomposição dos carbonatos), e um pico exotérmico a $828,8^{\circ} \mathrm{C}$, que poderá ser atribuído à formação de novas fases cristalinas (silicatos) após a decomposição da calcita e da dolomita.

A Fig. 3 compara os comportamentos dilatométricos, bem distintos, dos dois materiais. A argila apresenta um comportamento dilatométrico caracterizado por

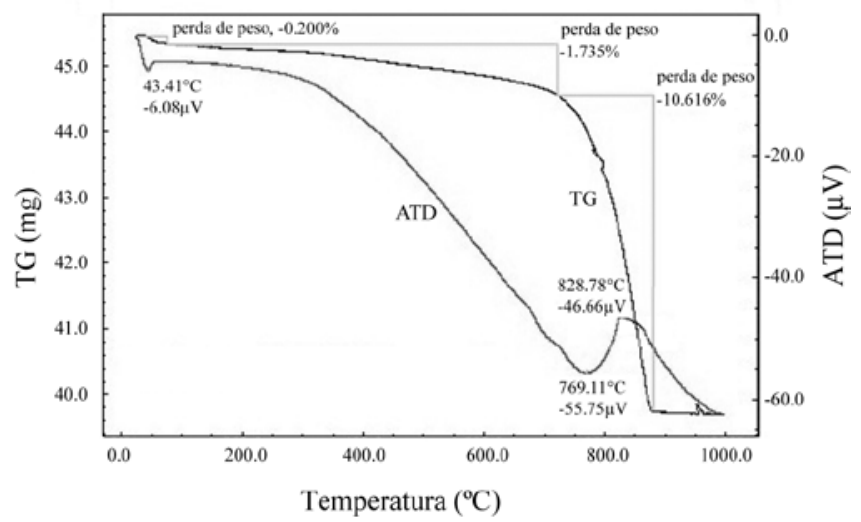

Figura 2: Análise térmica diferencial e termogravimétrica do rejeito de mármore e granito.

[Figure 2: Differential thermal analysis and thermal gravimetry (DTA and TG) of the marble and granite waste.]

uma expansão uniforme até cerca de $870{ }^{\circ} \mathrm{C}$, seguida de retração a partir de temperaturas em torno de $1000^{\circ} \mathrm{C}$. Este comportamento é típico das argilas predominantemente ilíticas [14]. O rejeito mostra uma forte contração a cerca de $800^{\circ} \mathrm{C}$, provavelmente causada pela formação de fase líquida devido à presença dos óxidos de metais alcalinos (Tabela I), seguida de uma expansão significativa a aproximadamente $900{ }^{\circ} \mathrm{C}$, o que confirma a formação de novas fases cristalinas, já observada por análise térmica: o óxido de cálcio resultante da decomposição dos carbonatos (calcita e dolomita) reage com os outros óxidos presentes no material formando mais anortita $\left(\mathrm{CaAl}_{2} \mathrm{Si}_{2} \mathrm{O}_{8}\right)$. Este comportamento é habitual em materiais com concentração elevada de óxido de cálcio [10], mas materiais argilosos com adições de resíduo de granito, que não contêm teores de óxido de cálcio elevados, não apresentam essa variação volumétrica [15].

As análises granulométricas dos materiais investigados

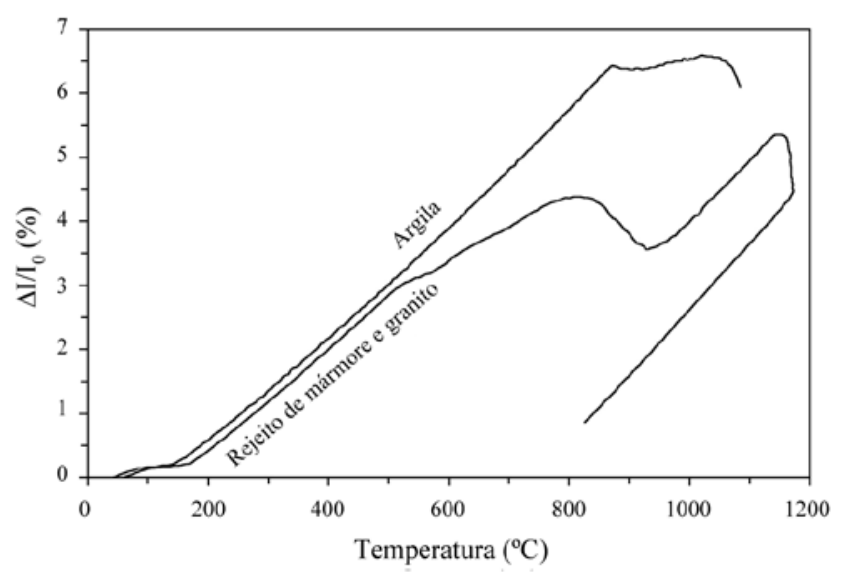

Figura 3: Comportamento dilatométrico da argila e do rejeito de mármore e granito.

[Figure 3: Dilatometric behavior of the clay and of the marble and granite waste.] 
nesse trabalho mostraram que $50 \%$ das partículas da argila apresentam diâmetro equivalente inferior a cerca de 5,0 $\mu \mathrm{m}$. $\mathrm{O}$ rejeito é constituído por partículas pequenas, porém com uma grande dispersão de tamanhos, variando de 2 a 100 $\mu \mathrm{m}$. O diâmetro equivalente médio das partículas é de 23,75 $\mu \mathrm{m}$, sendo que $90 \%$ das partículas apresentam diâmetros inferiores a $32,8 \mu \mathrm{m}$.

As adições de rejeito, principalmente de teores elevados, terão conseqüências no processamento cerâmico, quer em verde, quer durante na queima. Apesar de o processamento em verde não ter sido objeto deste estudo, convém lembrar que as diferenças na distribuição granulométrica e no comportamento plástico entre a argila e o rejeito (redutor de plasticidade) poderão acarretar mudanças no processo de conformação dos corpos cerâmicos e eventuais dificuldades de fabricação, já que os produtos de cerâmica vermelha são fabricados principalmente por extrusão. Também a etapa de secagem poderá ser afetada (facilitada) pela adição de altas quantidades de rejeito, mas os corpos secos poderão perder alguma resistência mecânica.

Durante a queima, as mudanças serão devidas principalmente a alterações da temperatura de formação de fase líquida e da quantidade de fase líquida formada. A Tabela I mostra que adições de rejeito à argila poderão provocar alterações significativas dos teores dos óxidos de cálcio e de ferro, mantendo-se a sílica e a alumina como componentes majoritários. $\mathrm{O}$ efeito fundente do terceiro óxido, muito mais forte para o $\mathrm{CaO}$ do que para o óxido de ferro, poderá ser explicado em termos do equilíbrio de fases nos sistemas $\mathrm{SiO}_{2}-$ $\mathrm{Al}_{2} \mathrm{O}_{3}-\mathrm{CaO}$ e $\mathrm{SiO}_{2}-\mathrm{Al}_{2} \mathrm{O}_{3}$-óxido de ferro [16].

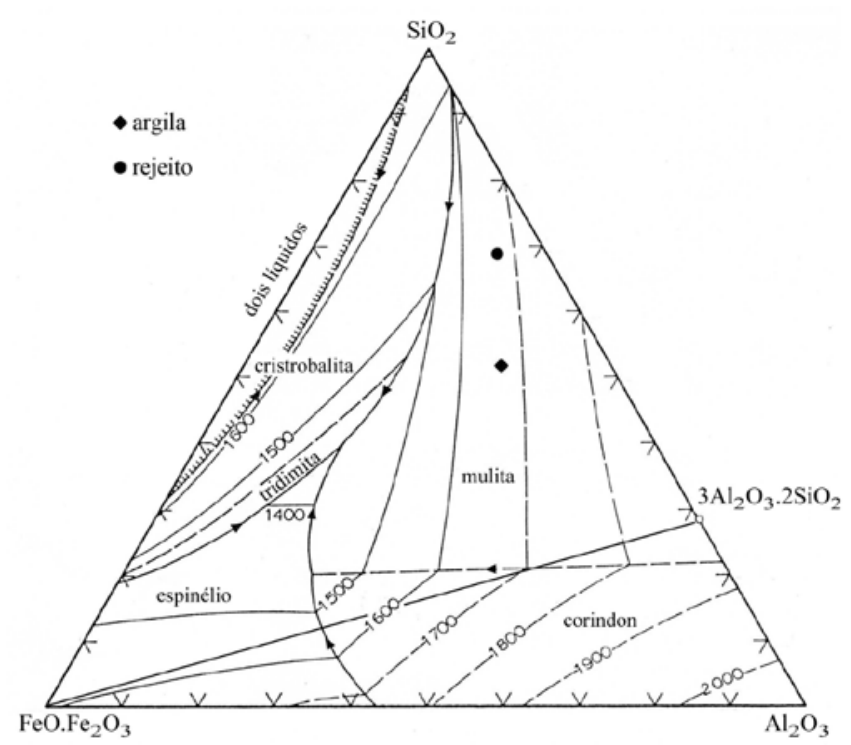

Figura 4: Diagrama de equilíbrio de fases, ao ar, do sistema $\mathrm{SiO}_{2}-$ $\mathrm{Al}_{2} \mathrm{O}_{3}-\mathrm{Fe}_{3} \mathrm{O}_{4}[16]$, mostrando a localização da argila e do rejeito. [Figure 4: Phase equilibrium diagram, in air, of the system $\mathrm{SiO}_{2}$ $\mathrm{Al}_{2} \mathrm{O}_{3}-\mathrm{Fe}_{3} \mathrm{O}_{4}$ [16], showing the location of the clay and of the waste material.]
Em ar, no sistema com o óxido de ferro (Fig. 4), o movimento da composição no sentido do rejeito não origina mudança de triângulo de compatibilidade de fases sólidas nem de temperatura de formação de fase líquida $\left(\sim 1400^{\circ} \mathrm{C}\right)$. Porém, teores crescentes de rejeito fazem com que a composição da mistura se aproxime do lado mulita-sílica do triângulo e, portanto, a quantidade de líquido formado diminui quando o teor de rejeito aumenta.

Já no sistema com o óxido de cálcio (Fig. 5), teores crescentes de rejeito poderão levar a composição da mistura do triângulo sílica-mulita-anortita para o triângulo de compatibilidade vizinho sílica-anortita-volastonita, onde a temperatura inicial de fusão é cerca de $200{ }^{\circ} \mathrm{C}$ mais baixa (teoricamente, de 1345 para $1170{ }^{\circ} \mathrm{C}$ ) e onde, no conjunto de fases compatíveis, a mulita é substituída pela volastonita.

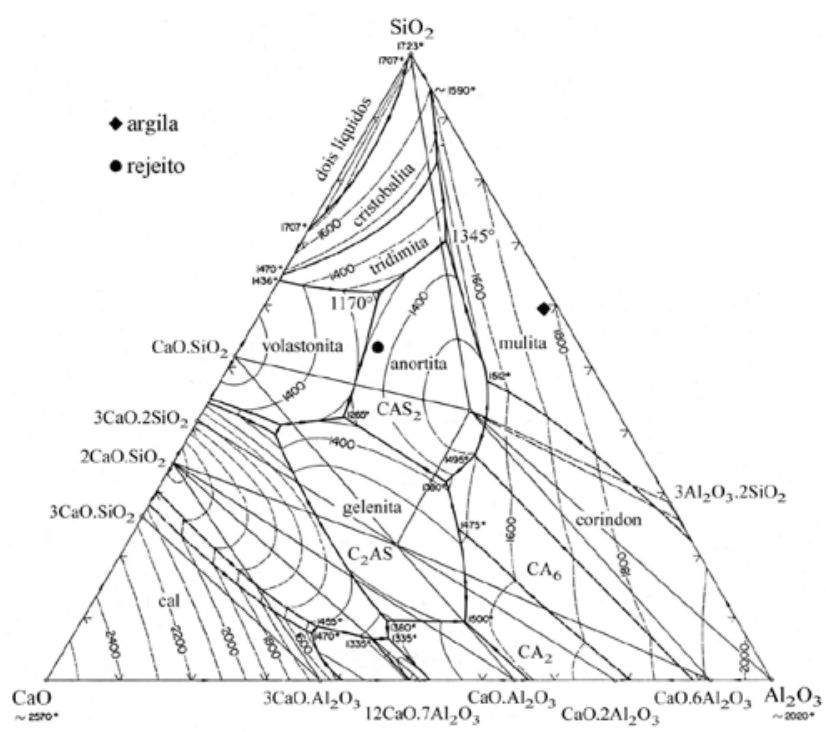

Figura 5: Diagrama de equilíbrio de fases do sistema $\mathrm{SiO}_{2}-\mathrm{Al}_{2} \mathrm{O}_{3}-$ $\mathrm{CaO}$ [16], mostrando a localização da argila e do rejeito.

[Figure 5: Phase equilibrium diagram of the system $\mathrm{SiO}_{2}-\mathrm{Al}_{2} \mathrm{O}_{3}-$ $\mathrm{CaO}$ [16], showing the location of the clay and of the waste material.]

No sistema real, com todos os componentes minoritários presentes, os efeitos discutidos acima se mantêm, mas ocorrem a temperaturas sempre mais baixas.

As Figs. 6 e 7 apresentam, respectivamente, a variação de massa específica aparente e absorção de água dos corpos de prova sinterizados, em função do teor de rejeito adicionado e da temperatura de sinterização. Pode-se notar que os valores de massa específica diminuem quando a concentração de rejeito aumenta e aumentam com a elevação da temperatura de sinterização. Os valores de absorção de água aumentam com o aumento da concentração de rejeito e diminuem quando a temperatura de sinterização se eleva. Os valores de densidade mais altos e de absorção de água mais baixos foram obtidos para as temperaturas mais elevadas (1100 


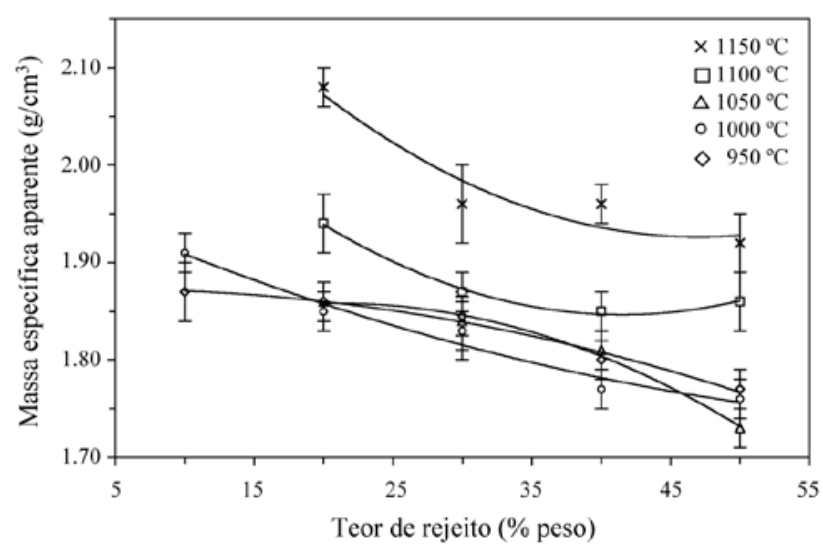

Figura 6: Massa específica aparente dos corpos de prova sinterizados em função do teor de rejeito e da temperatura de sinterização.

[Figure 6: Apparent density of sintered samples as a function of the waste content and the sintering temperature.]

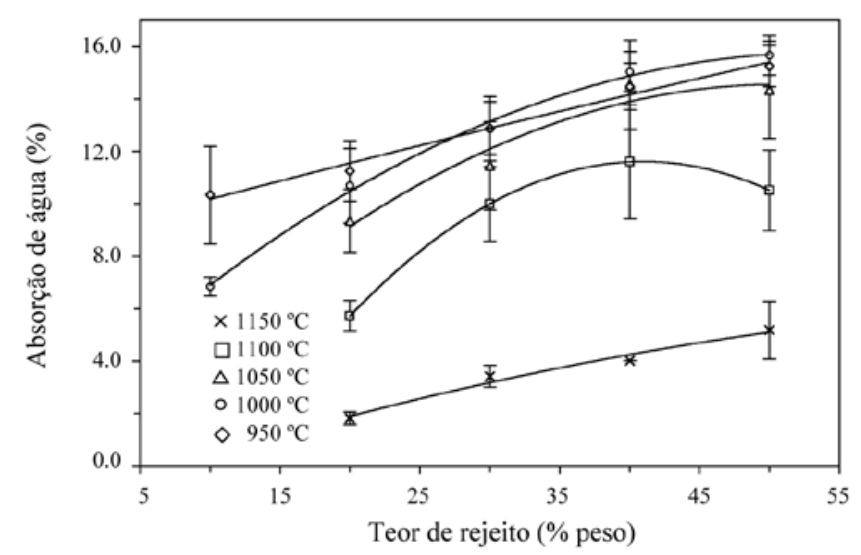

Figura 7: Absorção de água dos corpos de prova sinterizados em função do teor de rejeito e da temperatura de sinterização.

[Figure 7: Water absorption of sintered samples as a function of the waste content and the sintering temperature.]

e $1150{ }^{\circ} \mathrm{C}$ ), independentemente do teor do rejeito. Cabe salientar que, para todas as temperaturas de sinterização investigadas, os valores obtidos foram sempre compatíveis com os especificados pelas normas para uso em cerâmica vermelha $[17,18]$, ou seja, para a massa específica foram sempre superiores ao mínimo $\left(1,70 \mathrm{~g} / \mathrm{cm}^{3}\right)$, enquanto que para a absorção de água foram sempre inferiores ao máximo $(20 \%)$.

A Fig. 8 mostra a variação da tensão de ruptura à flexão dos corpos de prova em função da temperatura de sinterização e da concentração do rejeito de mármore e granito. Pode observar-se que, qualquer que seja a temperatura de sinterização, a tensão de ruptura tende a ser máxima em torno $30 \%$ de rejeito. Voltando à Fig. 5 e ao efeito fundente do $\mathrm{CaO}$, verifica-se que este teor de rejeito corresponde aproximadamente à composição que forma a quantidade de líquido máxima no início da fusão (e, simultaneamente, contém a quantidade mínima de mulita). Este fato não só confirma que o efeito fundente do $\mathrm{CaO}$ se sobrepõe ao do óxido de ferro (como se disse, teores crescentes óxido de ferro devidos a teores crescentes de rejeito farão com que a quantidade de líquido formado diminua), como também que o equilíbrio de fases previsto pelo diagrama pode ser extrapolado para temperaturas inferiores para contemplar o efeito da presença dos outros óxidos minoritários. Mostra ainda que, no sistema global, a temperatura inicial de fusão é inferior a qualquer das temperaturas de sinterização usadas. Será então a presença de fase líquida mais abundante nas composições contendo $\sim 30 \%$ de rejeito (fase vítrea à temperatura ambiente) que melhora a correspondente resistência mecânica.

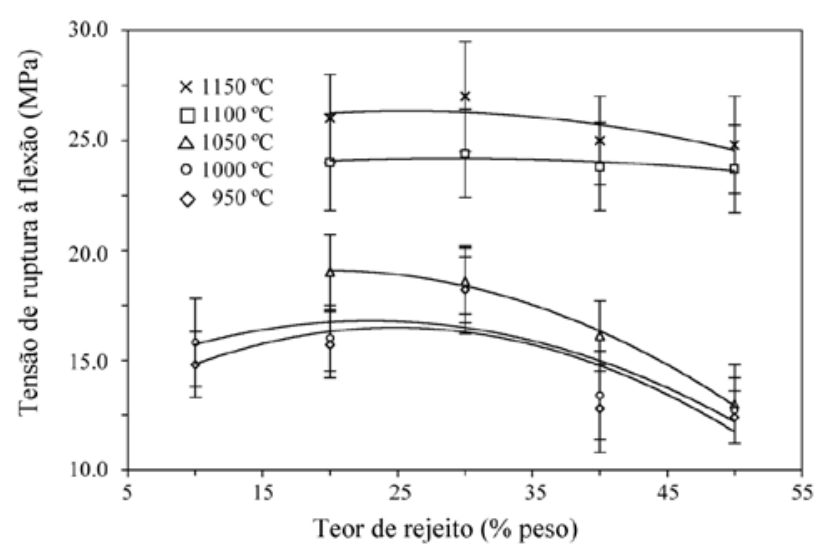

Figura 8: Tensão de ruptura à flexão dos corpos de prova sinterizados em função do teor de rejeito e da temperatura de sinterização.

[Figure 8: Flexural strength of sintered samples as a function of the waste content and the sintering temperature.]

Como seria de esperar, os valores máximos de tensão de ruptura foram obtidos para as temperaturas de 1100 e $1150{ }^{\circ} \mathrm{C}$, embora estas temperaturas sejam tecnologicamente altas para fabricação de produtos de cerâmica vermelha tais como tijolos maciços e blocos de alvenaria. Maiores quantidades de rejeito $(>30 \%)$ e temperaturas mais baixas $\left(<1100{ }^{\circ} \mathrm{C}\right)$ originam uma diminuição dos valores de resistência mecânica, o que pode ser atribuído a uma porosidade mais alta (massa específica mais baixa, como mostra a Fig. 4, com a conseqüente absorção de água mais alta, como mostra a Fig. 5). Cabe relembrar que mesmo os resultados obtidos a temperaturas mais baixas foram compatíveis com os especificados pelas normas para uso em cerâmica vermelha.

\section{CONCLUSÕES}

Os resultados apresentados neste trabalho demonstram que é possível adicionar concentrações elevadas de rejeito de mármore e granito a massas argilosas, sem prejudicar a qualidade e propriedades do produto final.

O processamento em verde não foi objeto deste estudo e convém lembrar que a adição de rejeito poderá dificultar 
o processo de conformação (usualmente, extrusão) e facilitar a etapa de secagem, com algum sacrifício da resistência mecânica dos corpos secos. Relativamente à queima, os corpos sinterizados apresentaram, em todas as temperaturas investigadas (950$1150^{\circ} \mathrm{C}$ ), propriedades melhores do que as especificadas pelas normas para a cerâmica vermelha, mostrando ser possível a incorporação de rejeito de mármore e granito na fabricação de materiais daquele tipo, mesmo em baixas temperaturas.

\section{REFERÊNCIAS}

[1] E. J. A. Perez, R. Terradas, M. R. Manent, M. Seijas, S. Martinez, "Inertization of industrial wastes in ceramic materials", Ind. Ceram. 16, 1 (1996) 7-10.

[2] M. Dondi, M. Marsigli, B. Fabbri, "Recycling of industrial and urban wastes in brick production - a review", Tile \& Brick Int. 13, 3 (1997) 218-225.

[3] M. S. H. Crespo, J. M. Rincón, "New porcelainized stoneware materials obtained by recycling of MSW incinerator fly ashes and granite sawing residues", Ceram. Int. 27 (2001) 713-720.

[4] P. Pisciella, S. Crisucci, A. Karamanov, M. Pelino, "Chemical durability of glasses obtained by vitrification of industrial wastes", Waste Management 21 (2001) 1-9.

[5] R. R. Menezes, G. A. Neves, H. C. Ferreira, "O estado da arte sobre o uso de resíduos como matérias-primas cerâmicas alternativas", Rev. Bras. Eng. Agr. Amb. 6, 2 (2002) 303-313.

[6] G. P. Souza, J. N. F. Holanda, "Densification behaviour of petroleum waste bearing clay-based ceramic bodies", Ceram. Int. 30 (2004) 99-104.

[7] S. N. Monteiro, L. A. Peçanha, C. M. F. Vieira, "Reformulation of roofing tiles body with addition of granite waste from sawing operations", J. Eur. Ceram. Soc. 24 (2004) 2349-2356.
[8] E. Monfort, J. E. Enrique, "Economia energética e vantagens meio ambientais da reutilização de resíduos", Cerâm. Ind. 1, 4-5 (1996) 14-20.

[9] NITES-Núcleo Regional de Informação Tecnológica do Espírito Santo, "Desperdício na Indústria de Mármore e Granito. Rochas de Qualidade”, Ed.118 (Jul-Ago-Set 1994).

[10] H. Thomas, G. Peer, "Mineral raw materials in the brick and tile industry-important parametres in the daily practice of the geoscientist", Part 2, J. ZI, 12 (2001) 20-26.

[11] Associação Brasileira de Normas Técnicas - ABNT, NBR 6480-85, "Determinação da massa específica e da absorção de água”, Rio de Janeiro, RJ (1985).

[12] Associação Brasileira de Normas Técnicas - ABNT, NBR 6462-97, "Determinação da carga de ruptura a flexão", Rio de Janeiro, RJ (1997).

[13] DIN 51090, "Testing of ceramic materials: bend test for wall and floor tiles" (1971).

[14] P. S. Santos, Ciência e Tecnologia de Argilas, Vol.1, $3^{\text {a }}$ edição. Ed. Edgard Blücher Ltda., S. Paulo, SP (1997) p. 214, 277-299.

[15] G. A. Neves, "Reciclagem de resíduos da serragem de granito para uso como matéria-prima cerâmica", Tese de Doutorado - UFPB, Campina Grande (2002).

[16] E. M. Levin, C. R. Robbins, H. F. McMurdie, "Phase Diagrams for Ceramists", The Am. Ceram. Soc., Columbus, Ohio (1974) Figs. 132, 2493.

[17] Associação Brasileira de Normas Técnicas - ABNT, NBR 7170-96, "Tijolo maciço cerâmico para alvenaria, especificações", Rio de Janeiro, RJ (1996).

[18]Associação Brasileira de Normas Técnicas - ABNT, NBR 7171-96, "Bloco cerâmico para alvenaria, especificações", Rio de Janeiro, RJ (1996).

(Rec. 12/02/2004, Rev. 14/04/2004, 31/08/2004, Ac. 10/09/2004) 